CLINICAL STUDY

\title{
Beta cell function after weight loss: a clinical trial comparing gastric bypass surgery and intensive lifestyle intervention
}

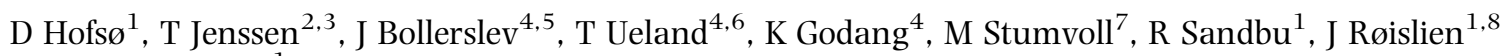 \\ and J Hjelmesæth ${ }^{1}$ \\ ${ }^{1}$ Department of Medicine, Morbid Obesity Centre, Vestfold Hospital Trust, PO Box 2168, 3103 Tonsberg, Norway, ${ }^{2}$ Institute of Clinical Medicine, \\ University of Tromsø, 9037 Tromsø, Norway, ${ }^{3}$ Section of Nephrology, Department of Medicine and ${ }^{4}$ Section of Endocrinology, Department of Medicine, \\ Oslo University Hospital Rikshospitalet, 0027 Oslo, Norway, ${ }^{5}$ Faculty of Medicine, University of Oslo, 0318 Oslo, Norway, ${ }^{6}$ Research Institute for \\ Internal Medicine, Oslo University Hospital Rikshospitalet, University of Oslo, O027 Oslo, Norway, ${ }^{7}$ Department of Medicine, University of Leipzig, \\ 04109 Leipzig, Germany and ${ }^{8}$ Department of Biostatistics, Institute of Basic Medical Sciences, University of Oslo, 0317 Oslo, Norway \\ (Correspondence should be addressed to D Hofsø; Email: dag.hofso@siv.no)
}

\begin{abstract}
Objective: The effects of various weight loss strategies on pancreatic beta cell function remain unclear. We aimed to compare the effect of intensive lifestyle intervention (ILI) and Roux-en-Y gastric bypass surgery (RYGB) on beta cell function.

Design: One year controlled clinical trial (ClinicalTrials.gov identifier NCT00273104).

Methods: One hundred and nineteen morbidly obese participants without known diabetes from the MOBIL study (mean (s.D.) age 43.6 (10.8) years, body mass index (BMI) 45.5 (5.6) kg/m² 84 women) were allocated to RYGB $(n=64)$ or ILI $(n=55)$. The patients underwent repeated oral glucose tolerance tests (OGTTs) and were categorised as having either normal (NGT) or abnormal glucose tolerance (AGT). Twenty-nine normal-weight subjects with NGT (age 42.6 (8.7) years, BMI 22.6 (1.5) $\mathrm{kg} / \mathrm{m}^{2}$, 19 women) served as controls. OGTT-based indices of beta cell function were calculated.

Results: One year weight reduction was 30\% (8) after RYGB and $9 \%(10)$ after ILI $(P<0.001)$. Disposition index (DI) increased in all treatment groups (all $P<0.05$ ), although more in the surgery groups (both $P<0.001$ ). Stimulated proinsulin-to-insulin (PI/I) ratio decreased in both surgery groups (both $P<0.001)$, but to a greater extent in the surgery group with AGT at baseline $(P<0.001)$. Post surgery, patients with NGT at baseline had higher DI and lower stimulated PI/I ratio than controls (both $P<0.027)$.

Conclusions: Gastric bypass surgery improved beta cell function to a significantly greater extent than ILI. Supra-physiological insulin secretion and proinsulin processing may indicate excessive beta cell function after gastric bypass surgery.
\end{abstract}

European Journal of Endocrinology $164231-238$

\section{Introduction}

Obesity is a major risk factor for type 2 diabetes, with approximately one out of three morbidly obese subjects (body mass index (BMI) $\geq 40 \mathrm{~kg} / \mathrm{m}^{2}$ or BMI $\geq 35 \mathrm{~kg} / \mathrm{m}^{2}$ with at least one obesity-related comorbidity) having type 2 diabetes (1). Reduced insulin sensitivity and beta cell dysfunction represent the core pathophysiological defects in type 2 diabetes (2). It is well known that weight reduction enhances insulin sensitivity in obese subjects (3), with this contributing to the improvement in glycaemic control reported after lifestyle intervention (4) and bariatric surgery (5). By contrast, the association between weight reduction and restoration of beta cell function is less clear. Modest weight loss induced by diet alone (6) or in combination with exercise (7) in older non-diabetic overweight and obese subjects has been shown to enhance beta cell function. Moreover, results from the Diabetes Prevention Programme which predominantly included obese, middleaged subjects with impaired glucose tolerance (IGT) indicate improved insulin secretion relative to insulin sensitivity after 1 year of intensive lifestyle intervention (ILI) (8). By contrast, 24 months of diet and endurance exercise did not improve beta cell function in Japanese Americans with IGT (9). Furthermore, recovery of beta cell function has been reported after bariatric surgery (10-12). Increased insulin secretion post surgery could contribute to high remission rates of type 2 diabetes after bariatric surgery (5) as well as to postprandial hypoglycaemia, a phenomenon that has drawn much attention recently $(13,14)$.

Given this background, we aimed to compare in morbidly obese patients without known diabetes commercial use, distribution, and reproduction in any medium, provided the original work is properly cited. 
the 1 year effect of ILI (diet and physical activity) and Roux-en-Y gastric bypass on beta cell function as assessed by oral glucose tolerance test- (OGTT) derived indices.

\section{Methods}

\section{Participants and study design}

This is an ancillary study to the MOBIL study (Morbid Obesity treatment, Bariatric surgery versus ILI study, ClinicalTrials.gov identifier: NCT00273104) (15). It includes a subset of 119 morbidly obese participants without known diabetes who underwent an OGTT before and after intervention. In addition, 29 normalweight $\left(\mathrm{BMI}<25 \mathrm{~kg} / \mathrm{m}^{2}\right)$ subjects with normal glucose tolerance (NGT) served as a control group (data from 27 of these subjects have been published previously (16)).

The MOBIL study aimed to address changes in several health outcomes related to obesity, with details concerning the design and intervention published previously (15). In short, this 1 year controlled clinical trial included 146 consecutively recruited morbidly obese subjects predominantly of European descent and was conducted at a public tertiary care centre in Norway between December 2005 and June 2009. Patients in the surgery group were allocated to laparoscopic Roux-en-Y gastric bypass, whereas patients who chose lifestyle intervention were referred to a rehabilitation centre specialising in the care of morbidly obese patients (Evjeklinikken A/S). The 1 year lifestyle programme aimed to induce a weight loss of at least $10 \%$ and comprised of four stays at the centre lasting for either 1 week or 4 weeks (total 7 week stay). The daily programme was divided between organised physical activity (3-4h) and different psychosocially oriented interventions. No special diet or weight loss drugs were prescribed, but patients were encouraged to follow the guidelines of the Norwegian National Council of Nutrition. Outside of these stays, patients were contacted by phone once every 2 weeks. The patients were encouraged to self-monitor their eating habits and physical activity, as well as to visit their general practitioner regularly.

The regional ethics committee of the Southern Norway Regional Health Authority approved the study. Written informed consent was provided by all participants.

\section{Oral glucose tolerance test}

A $75 \mathrm{~g}$ OGTT was performed at $0800 \mathrm{~h}$ after an overnight fast, with venous blood samples obtained at 0,30 and 120 min for determination of serum glucose, insulin, C-peptide and proinsulin. Treatment with hypoglycaemic agents was terminated 2 weeks prior to the OGTT for patients receiving such treatment. On the day of the OGTT, no medications were taken prior to the test.
Glucose tolerance status was determined according to the criteria of the World Health Organization (17). NGT was defined as fasting glucose $<6.1 \mathrm{mmol} / \mathrm{l}$ and $2 \mathrm{~h}$ glucose $<7.8 \mathrm{mmol} / \mathrm{l}$. The abnormal glucose tolerance (AGT, fasting glucose $\geq 6.1 \mathrm{mmol} / \mathrm{l}$ and/or $2 \mathrm{~h}$ glucose $\geq 7.8 \mathrm{mmol} / \mathrm{l}$ ) groups included subjects with impaired fasting glucose (IFG), IGT and new onset diabetes mellitus (NODM). Post challenge hypoglycaemia was defined as $2 \mathrm{~h}$ glucose $<2.8 \mathrm{mmol} / \mathrm{l}$.

\section{Calculations}

Several estimates of insulin secretion and insulin sensitivity were initially assessed using indices including the available glucose and insulin measurements from the OGTT (18-20). However, the insulin sensitivity indices of Belfiore et al. (19) and Stumvoll et al. (20), comprising of glucose and insulin concentrations at $120 \mathrm{~min}$, seemed to overestimate post surgery insulin sensitivity (significantly higher median values than NGT controls, both $P \leq 0.001$ ) and were therefore not included in the analyses. Consequently, the computerbased homoeostasis model assessment of insulin sensitivity (HOMA-S) was preferred as the insulin sensitivity index (18).

Insulin secretion was estimated using the insulinogenic index $\left(\Delta \operatorname{Ins}_{30} / \Delta \mathrm{Gluc}_{30}\right)$, the ratio of the total area under the insulin curve to the total area under the glucose curve (total $\mathrm{AUC}_{\text {Ins/Gluc }}$ ) and the Stumvoll first phase index (first phase est $_{1}: 1283+1.829 \times$ Ins $_{30}$ $-138.7 \times$ Gluc $\left._{30}+3.772 \times \mathrm{Ins}_{0}\right)(20)$. Because insulin secretion is determined in part by the prevailing insulin sensitivity, the disposition index (DI), which is the product of insulin sensitivity and insulin secretion, yields a better measure of beta cell function (21). Based on the above-mentioned indices of insulin secretion, three alternative DIs were calculated.

Circulating proinsulin-to-insulin (PI/I) ratio, especially stimulated PI/I ratio (22), has previously been used as an estimate of the beta cell's ability to transform proinsulin to insulin. Indeed, elevated PI/I ratio has been associated with IGT (22) and reduced insulin secretion (23). PI/I ratios in a fasting and stimulated state (30 min after glucose ingestion) were therefore calculated.

\section{Laboratory analyses}

HbAlc was analysed using HPLC on Tosoh HLC-723 G7 (Tosoh Corporation, Tokyo, Japan). Serum samples from the OGTT were separated after $30 \mathrm{~min}$ and either stored at $-80^{\circ} \mathrm{C}$ or analysed the same day (glucose). Analyses of glucose were performed using dry reagent slide technology on the Vitros 950 Analyser until November 2006 and the Vitros FS 5.1 Analyser (Ortho-Clinical Diagnostics, New York, NY, USA) thereafter. Serum levels of insulin, C-peptide and proinsulin (Millipore 
Corporation, Billerica, MA, USA) were measured by RIA. All samples were measured in duplicate, with serial samples from a given individual run at the same time. Intra- and inter-assay coefficient of variation were $<10 \%$ for all assays.

\section{Statistical analysis}

Data are presented as mean (s.D.) or number (\%) unless otherwise specified. Skewed data were either transformed using natural logarithms to approximate normality or analysed using non-parametric tests. Between-group comparisons were analysed using oneway ANOVA with post hoc comparisons (least significant difference, LSD), Mann-Whitney $U$ test, $\chi^{2}$, two-way ANOVA and analysis of covariance (ANCOVA) including gender, age, BMI at baseline and baseline value as covariates. Within-group comparisons between baseline and follow-up variables were compared using paired samples $t$-test. Correlations were calculated with Pearson's correlation coefficients. Linear regression analyses were used to i) explore a potential hyperbolic relationship between HOMA-S and measures of insulin secretion $(95 \%$ CI of the regression coefficient $(\beta)$ in the equation $\ln ($ insulin secretion $)=$ constant + $\beta \times \ln$ (insulin sensitivity) must include -1 and exclude 0 ) and ii) identify possible predictors of change in DI and PI/I ratios (age, gender, change in smoking status (stopped/unchanged/started), family history of type 2 diabetes (yes/no), glucose tolerance status (NGT/AGT), change in physical activity (became inactive/unchanged/became active), treatment choice (surgery/lifestyle), and percentage weight reduction). The significance level was $P<0.05$. Statistical analyses were performed using SPSS 16.0 (SPSS, Inc., Chicago, IL, USA).

\section{Results}

\section{Baseline characteristics of participants}

The 64 patients assigned to gastric bypass were on average 5 years younger and $13 \mathrm{~kg}$ heavier than the 55 patients in the lifestyle groups (both $P<0.005$ ). Otherwise, within the NGT and AGT groups, the surgery and lifestyle groups were comparable with respect to gender and measures of glucose homoeostasis (Table 1). In both the surgery and lifestyle groups, patients with AGT had higher HbAlc, were less insulin sensitive and had lower insulin secretion than patients with NGT (Table 1). In the AGT surgery group, 9 subjects had IFG, 12 subjects had IGT and 11 subjects had NODM, while in the AGT lifestyle group, 1 subject had IFG, 10 subjects had IGT and 11 subjects had NODM.

Table 1 Participant characteristics at baseline and at 1-year follow-up. Data are given as mean (s.D.) or $n$ (\%). AGT is defined by fasting glucose $\geq 6.1 \mathrm{mmol} / \mathrm{l}$ and $/$ or $2 \mathrm{~h}$ glucose $\geq 11.1 \mathrm{mmol} / \mathrm{l}$.

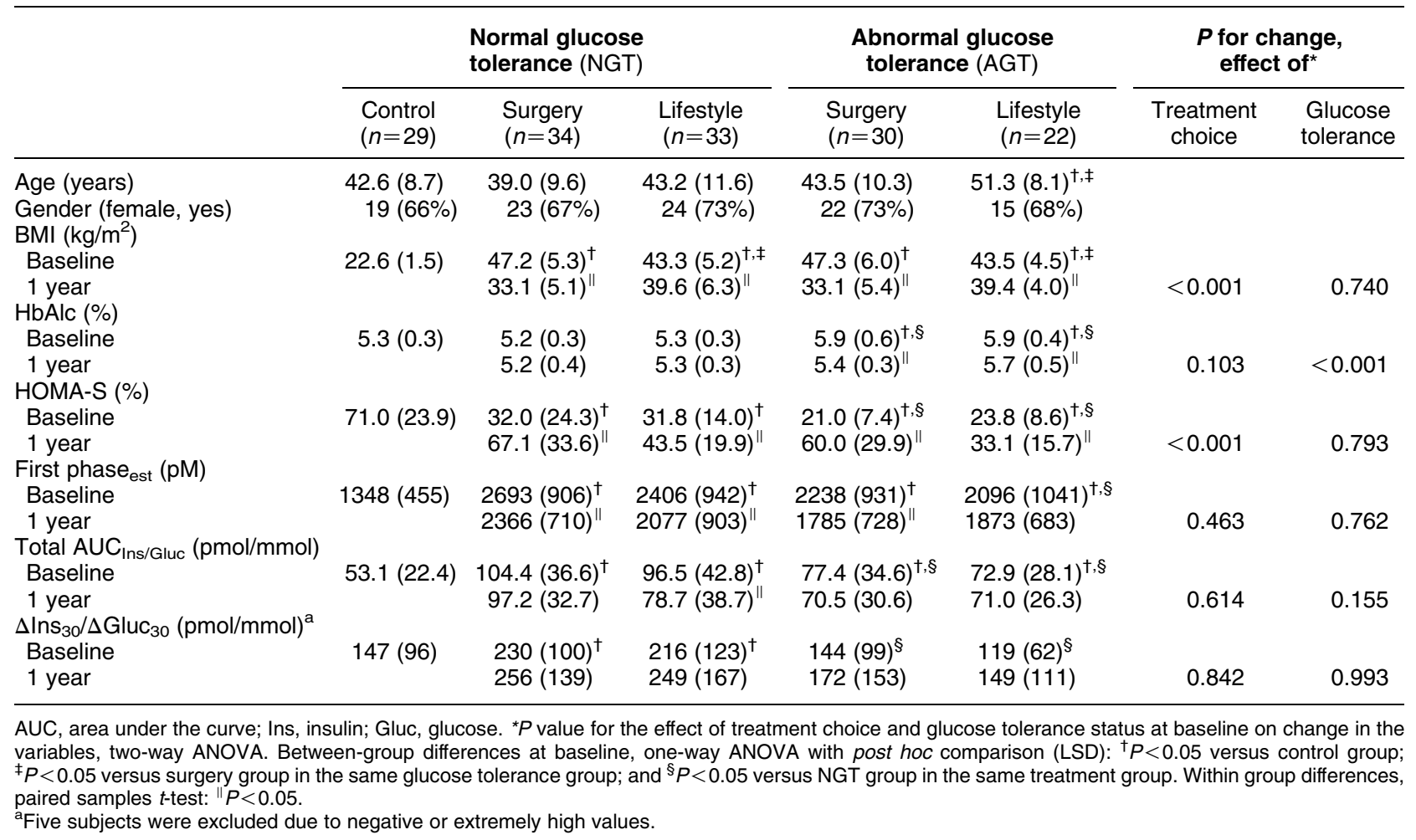



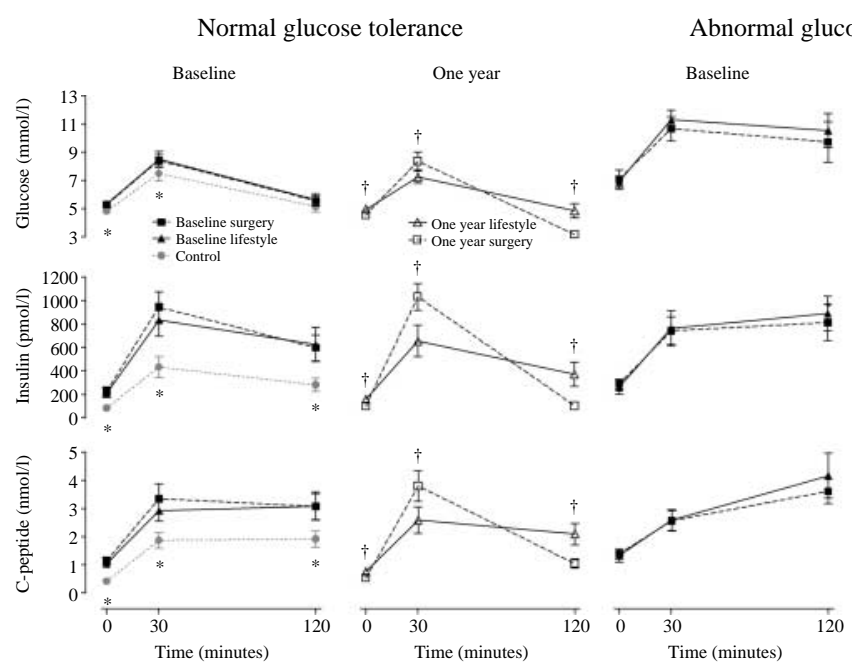

\section{Changes in weight, energy intake, medication and glucose tolerance}

Mean (S.D.) weight reduction in the merged surgery and lifestyle groups was $30(8) \%$ and $9(10) \%$ respectively $(P<0.001)$. Self-reported energy intake was significantly lower after surgical treatment than after lifestyle intervention (NGT and AGT groups combined: from 11.8 (5.1) to 6.9 (1.8) MJ/day and from 12.0 (3.6) to 8.6 (1.9) $\mathrm{MJ} /$ day respectively, $P<0.001)$. At baseline, none of the participants used hypoglycaemic agents, whereas three patients who chose surgery and two patients who chose lifestyle intervention were taking weight loss medications. After surgery, neither hypoglycaemic nor weight loss medications were used. By contrast, after 1 year of lifestyle intervention, five patients used hypoglycaemic agents (metformin) and three patients were taking weight loss medication. AGT was resolved in all gastric bypass surgery patients and in $41 \%$ (9 out of 22) of lifestyle intervention patients $(P<0.001)$.

\section{Glucose, insulin and C-peptide during the OGTT}

With the exception of no change in glucose and an increase in insulin and C-peptide at $30 \mathrm{~min}$ after surgical treatment, both interventions resulted in a reduction in glucose, insulin and C-peptide at all time points in both glucose tolerance groups (Fig. 1). At 1 year, glucose, insulin and C-peptide in the surgery groups were lower at 0 and $120 \mathrm{~min}$ and higher at $30 \mathrm{~min}$ than in the lifestyle groups. Post challenge hypoglycaemia $(<2.8 \mathrm{mmol} / \mathrm{l})$ was significantly more prevalent after surgical treatment than after lifestyle intervention (NGT and AGT groups combined: 23 vs $4 \%, P=0.002)$, but did not differ significantly between the NGT and AGT groups $(P=0.768)$.

\section{Insulin sensitivity and insulin secretion}

HOMA-S increased after both interventions, though to a greater extent in the NGT and AGT surgery groups than in the corresponding lifestyle groups (Table 1). The changes in the three indices estimating insulin secretion during the OGTT yielded diverging results. While total $\mathrm{AUC}_{\text {Ins/Gluc }}$ and first phase est $_{\text {decreased or }}$ tended to decrease after both interventions in both glucose tolerance groups, the opposite was the case for $\Delta \operatorname{Ins}_{30} / \Delta \operatorname{Gluc}_{30}($ Table 1$)$.

\section{Disposition index}

Pairing HOMA-S with the indices of insulin secretion in subjects with NGT at baseline $(n=96)$ showed that the combination of HOMA-S and first phase est was closest to forming a hyperbola: HOMA-S and first phase $_{\text {est }}(\beta=-0.869,95 \%$ CI $(-0.971$ to -0.766$)$, $n=94)$; HOMA-S and total $\mathrm{AUC}_{\text {Ins/Gluc }}(\beta=-0.796$, $95 \% \mathrm{CI}(-0.922$ to $-0.671, n=94)$; and HOMA-S and $\Delta \operatorname{Ins}_{30} / \Delta$ Gluc $_{30}(\beta=-0.51595 \%$ CI $(-0.697$ to $-0.334), n=90)$. This combination was therefore used when calculating the DI presented.

Figure $2 \mathrm{~A}$ and $\mathrm{B}$ depict the 1 year changes in first phase $_{\text {est }}$ and HOMA-S according to glucose tolerance status at baseline in the surgically and conservatively treated groups. The first phase ${ }_{\text {est }}$ in relation to HOMA-S shifted to the right after treatment in both the surgery and lifestyle groups. These findings are consistent with increased insulin secretion relative to insulin sensitivity after both interventions as verified by increased DI in subjects with NGT and AGT in the surgery and lifestyle groups (Fig. 2C). However, the DI increased significantly more after surgical treatment than after lifestyle intervention in both glucose tolerance groups (Fig. 2C). Notably, at 1 year, the DI in the NGT surgery group was even higher than in NGT controls $(P<0.001)$. 


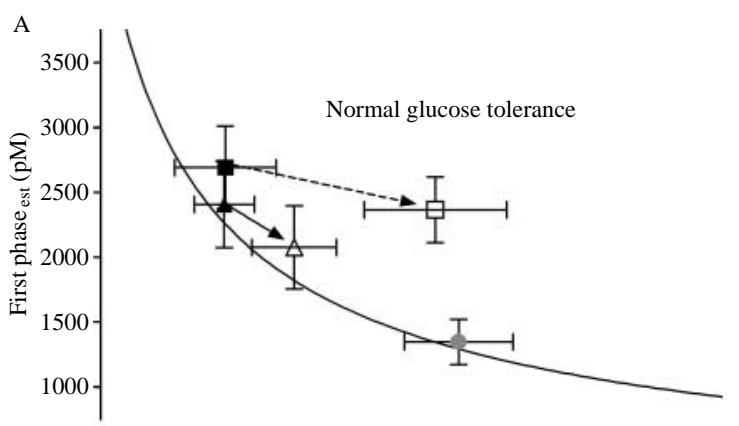

Baseline surgery $\square$ One year surgery $\Delta$ Baseline lifestyle $\Delta$ One year lifestyle $\bullet$ Control

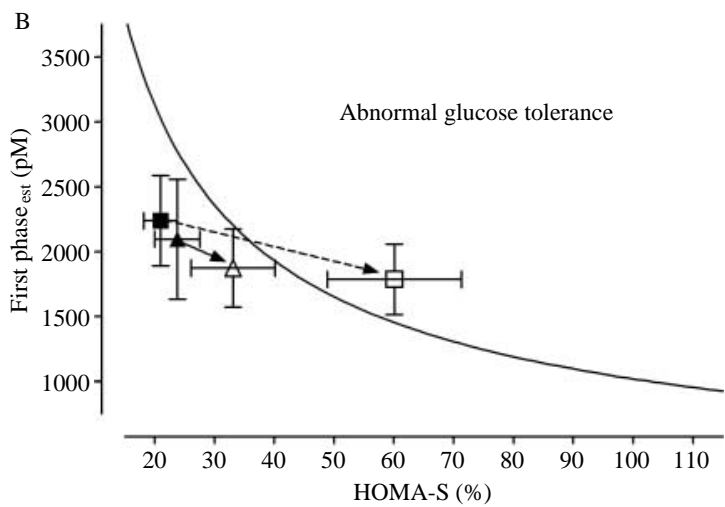

$\mathrm{C}$

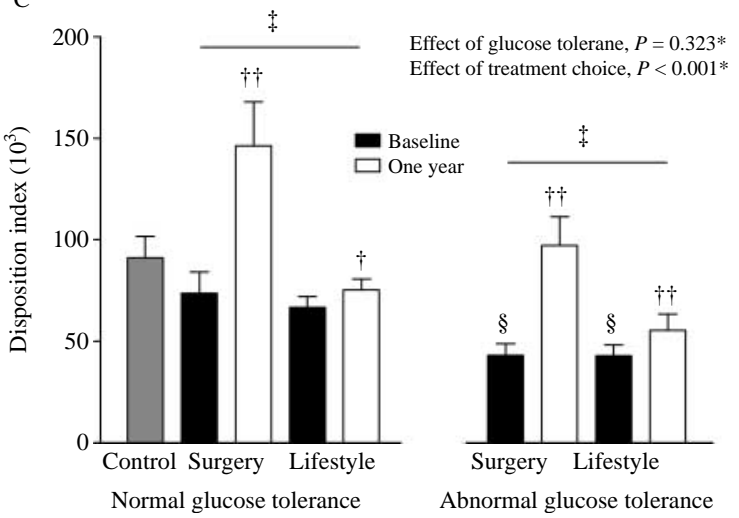

Figure 2 Mean HOMA-S plotted against first phase est $_{\text {in }}$ controls and morbidly obese subjects with normal glucose tolerance $(A)$ and abnormal glucose tolerance (B) before and 1 year after gastric bypass and lifestyle intervention. The curve represents the regression line of the natural logarithm of estimated insulin secretion as a linear function of the natural logarithm of estimated insulin sensitivity for all participants with normal glucose tolerance at baseline. The bar graph $(C)$ represents mean value of the corresponding disposition indices. Error bars represent $95 \% \mathrm{Cls}$. ${ }^{*} P$ value for the effect of treatment choice and glucose tolerance status at baseline on change in disposition index, two-way ANOVA. ${ }^{\dagger} P<0.05,{ }^{\dagger \dagger} P<0.001,1$ year versus baseline, paired samples $t$-test. ${ }^{\ddagger} P<0.001$, between group (surgery versus lifestyle), changes in disposition index within the same glucose tolerance group, ANCOVA with adjusting for gender, age and BMI at baseline and baseline value. ${ }^{\S} P<0.001$, normal glucose tolerance versus abnormal glucose tolerance within the same intervention group at baseline, independent samples $t$-test.
Exchanging first phase est $_{\text {with total }} \mathrm{AUC}_{\text {Ins/Gluc }}$ when calculating the alternative DI yielded similar results to those described above (data not shown).

\section{PI/I ratios}

The reduction in stimulated PI/I ratio was greatest after surgical treatment and was most pronounced among those with AGT (Fig. 3A). Fasting PI/I ratio was significantly reduced only in surgically treated patients with AGT (Fig. 3B). By contrast, stimulated and fasting PI/I ratios changed significantly neither in the NGT group nor in the AGT group after lifestyle intervention. At 1 year, stimulated PI/I ratio in the NGT surgery group was even lower than in the NGT control group $(P=0.027)$.

\section{Predictors of improved beta cell function}

In the whole study population, percentage weight change was correlated with both change in DI $(r=-0.56$, $P<0.001)$ and change in stimulated PI/I ratio $(r=0.29$, $P=0.001)$. Furthermore, there was a significant correlation between change in DI and change in stimulated PI/I ratio $(r=-0.31, P=0.001)$. The changes in fasting and stimulated PI/I ratios were moderately correlated $(r=0.41, P<0.001)$, whereas changes in fasting PI/I ratio correlated with neither weight nor DI changes.

The multiple linear regression analyses showed that i) treatment choice remained associated with change in DI $(\beta=0.337, P=0.008)$ and stimulated PI/I ratio $(\beta=-0.339, P=0.022)$; ii) glucose tolerance status at baseline remained associated with change in stimulated PI/I ratio $(\beta=-0.297, P=0.002)$; and iii) weight change remained associated with change in DI $(\beta=-0.329, P=0.008)$ but not with change in stimulated PI/I ratio $(\beta=-0.027, P=0.849)$.

\section{Discussion}

The aim of the present study was to compare the effects of Roux-en-Y gastric bypass and ILI on beta cell function in morbidly obese patients. Our results demonstrate that insulin sensitivity-adjusted insulin secretion was significantly greater after gastric bypass than after lifestyle intervention. In addition, significant reductions in PI/I ratios in the surgery groups were observed.

\section{Strengths and weaknesses of the study}

The main strength of the study is the controlled design. The limitations are the use of OGTT-derived indices not validated in gastric bypass-operated patients, the use of indices for the calculation of DI which did not fully 

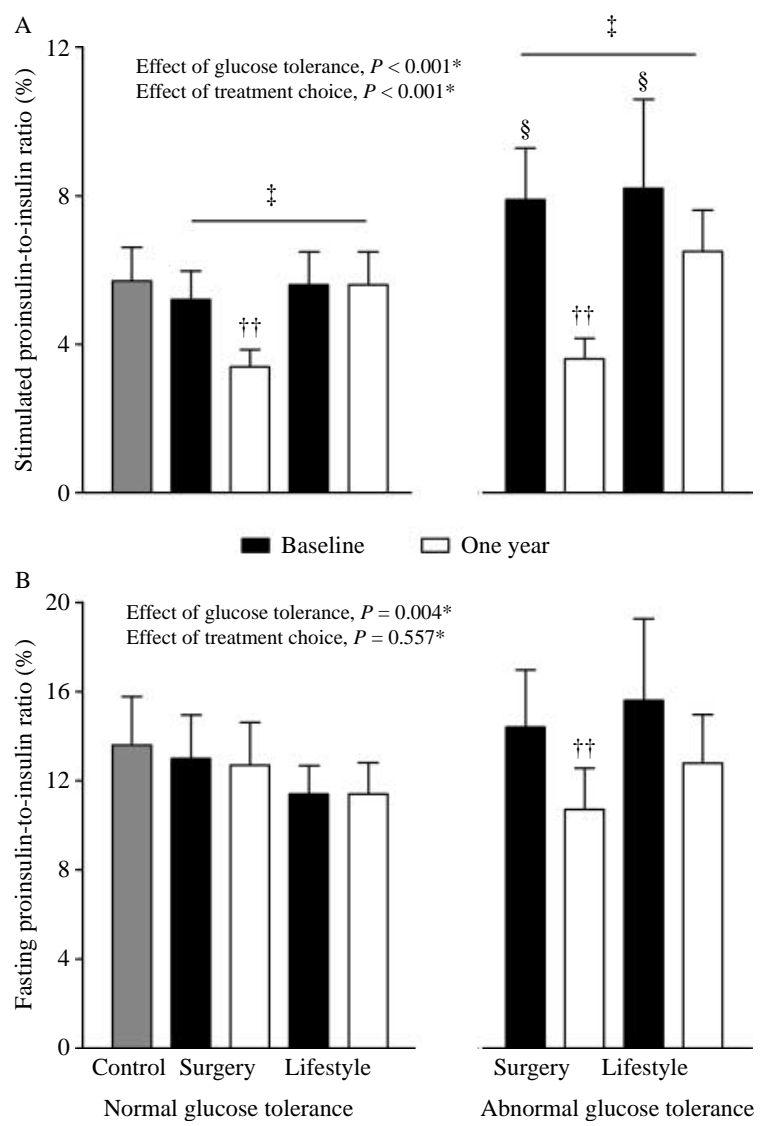

Figure 3 Mean stimulated $(A)$ and fasting $(B)$ proinsulin-to-insulin ratios in controls and morbidly obese subjects with normal and abnormal glucose tolerance before and 1 year after gastric bypass and lifestyle intervention. Error bars represent $95 \% \mathrm{Cls}$. ${ }^{*} P$ value for the effect of treatment choice and glucose tolerance status at baseline on change in disposition index, two-way ANOVA. ${ }^{t \dagger} P<0.001,1$ year versus baseline, paired samples $t$-test. ${ }^{\ddagger} P<0.001$, between groups (surgery versus lifestyle), changes in disposition index within the same glucose tolerance group, ANCOVA with adjusting for gender, age and BMI at baseline and baseline value. ${ }^{\S} P<0.001$, normal glucose tolerance versus abnormal glucose tolerance within the same intervention group at baseline, independent samples $t$-test.

satisfy the criteria for a hyperbolic relationship, the lack of gut hormone analyses, the non-randomised design and the inclusion of predominantly white subjects.

\section{Comparison with other studies}

In line with the Diabetes Prevention Programme (8) and two smaller weight loss studies $(6,7)$, we confirm that lifestyle intervention is associated with improved insulin sensitivity-adjusted insulin secretion. A positive effect of weight reduction on beta cell function has also been shown in a longitudinal study in Pima Indians (24). Contrasting previous results and the results of the present study, DI did not increase after 24 months of lifestyle intervention in a study of Japanese Americans with IGT (9). Since the improvement in insulin secretion may be proportional to the amount of weight loss (24), these differences may partly be explained by a modest weight reduction $(2.6 \%)$ in the latter study (9). This notion is further supported by our own results, which demonstrate that improvement in DI is partly explained by weight reduction. Furthermore, increased DI after gastric bypass is in line with some previous studies addressing insulin secretion after bariatric surgery in subjects with various degrees of glucose tolerance $(11,12)$. However, in contrast with our findings, Morinigo et al. (10) failed to demonstrate an increase in insulin secretory capacity to i.v. glucose in subjects with NGT or IGT 1 year after gastric bypass when accounting for prevailing insulin sensitivity. This discrepancy might have several explanations. First, we included a higher number of patients than Morinigo et al., and, second, our use of an OGTT-derived DI may have yielded a greater increase in the DI (11).

The pattern of change in the DI calculated by total $\mathrm{AUC}_{\text {Ins/Gluc }}$ and HOMA-S resembled that of the DI based

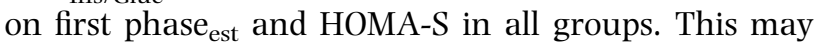
indicate that both early and late phase insulin section increased after both treatments.

A decrease in both fasting and stimulated PI/I ratios in the AGT surgery group further supports improved beta cell function after gastric bypass. The results are also partly in line with some $(12,25)$, but not all (26), previous studies reporting reduced fasting PI/I ratio after bariatric surgery in morbidly obese subjects with NGT and AGT. To the best of our knowledge, the possible effect of gastric bypass on stimulated PI/I ratio has not been reported previously. Our finding of a greater reduction in the PI/I ratios in subjects with AGT than in those with NGT may indicate that the improvement in insulin processing after gastric bypass is greatest in those who need it the most. By contrast, no significant reductions in the PI/I ratios were observed in both the NGT and the AGT groups after lifestyle intervention. However, the results correspond with those of a study reporting no reduction in fasting PI/I ratio in obese women with type 2 diabetes after diet induced weight loss (25).

Overall beta cell function was ameliorated to a greater extent after gastric bypass surgery than after lifestyle intervention. Since improvement in DI was independently associated with weight reduction, greater weight loss in the surgery groups than in the lifestyle groups could clearly explain some of the differences. However, it should be noted that surgical treatment also independently predicted improvements in DI and that improvements in stimulated PI/I ratio was associated with surgical treatment and not with weight reduction. The latter findings indicate that the improvements in beta cell function may be partly related to the surgical procedure per se and not only to weight reduction.

One year after surgery, post challenge glucose, insulin and C-peptide dropped sharply after an initial rise, with 
all values relatively high at $30 \mathrm{~min}$ and low at $120 \mathrm{~min}$ in both glucose tolerance groups. Specially worth noting is the high prevalence of post challenge hypoglycaemia. As demonstrated in this and previous studies, excessive insulin secretion may occur after gastric bypass $(13,25)$. Although the present study was not designed to explore the pathophysiological mechanisms for post bypass hyperinsulinaemia, it might be speculated that bypassing the gastric ventricle causes rapid absorption of glucose and consequently high glucose levels immediately after glucose ingestion. Indeed, we and others $(13,25)$ have reported elevated glucose levels $30 \mathrm{~min}$ after a glucose load in gastric bypass patients. Hyperglycaemia may in turn stimulate insulin secretion and thereby contribute to the observed hyperinsulinaemia. However, it is also very likely that other factors are involved, with a few publications recently addressing this phenomenon $(13,14)$. Some researchers argue that post-gastric bypass hyperinsulinaemia may be explained by the increase in gut hormones such as glucagon-like peptide 1 (GLP1) and gastric inhibitory peptide, which follows the rearrangement of the intestine $(13,25)$. Alternatively, but not mutually exclusive, pathologic overgrowth of pancreatic beta cells, possibly stimulated by GLP1, after bypass surgery may result in hypersecretion of insulin (14).

Finally, improved glycaemic control caused by enhanced insulin sensitivity after weight loss may in turn reduce the toxic effect of glucose on the pancreatic beta cells and thereby increase insulin secretion. This would partly explain the improved beta cell function observed after lifestyle intervention in both the present study and others like it (6-8).

\section{Conclusions}

In summary, beta cell function improved in subjects with both NGT and AGT after both interventions, although this was more pronounced after Roux-en-Y gastric bypass. Notably, supra-physiological insulin secretion and proinsulin processing may point towards excessive beta cell function after gastric bypass surgery. This may possibly contribute to improved glycaemic control in patients with AGT but also to postprandial hypoglycaemia observed after this procedure. Future studies addressing the same themes should be longitudinal, use both i.v. and oral techniques for the estimation of beta cell function and include gut hormones.

\section{Declaration of interest}

The authors declare that there is no conflict of interest that could be perceived as prejudicing the impartiality of the research reported.

\section{Funding}

D Hofsø has received unrestricted educational grants from Novo Nordisk A/S.

\section{Acknowledgements}

We thank the following employees at the Morbid Obesity Centre at Vestfold Hospital Trust: Berit Mossing Bjørkås, Linda Mathisen and Heidi Omre Fon for their assistance with sampling and logistics, and Matthew McGee for proofreading the manuscript.

\section{References}

1 Hofsø D, Jenssen T, Hager H, Røislien J \& Hjelmesæth J. Fasting plasma glucose in the screening for type 2 diabetes in morbidly obese subjects. Obesity Surgery 201020 302-307. (doi:10.1007/ s11695-009-0022-5)

2 Stumvoll M, Goldstein BJ \& van Haeften TW. Type 2 diabetes: principles of pathogenesis and therapy. Lancet $2005 \mathbf{3 6 5}$ 1333-1346. (doi:10.1016/S0140-6736(05)61032-X)

3 Golay A, Felber JP, Dusmet M, Gomez F, Curchod B \& Jequier E. Effect of weight loss on glucose disposal in obese and obese diabetic patients. International Journal of Obesity 19859 181-191.

4 Knowler WC, Barrett-Connor E, Fowler SE, Hamman RF, Lachin JM, Walker EA, Nathan DM \& Diabetes Prevention Program Research Group. Reduction in the incidence of type 2 diabetes with lifestyle intervention or metformin. New England Journal of Medicine 2002346 393-403. (doi:10.1056/NEJMoa012512)

5 Sjöström L, Lindroos AK, Peltonen M, Torgerson J, Bouchard C, Carlsson B, Dahlgren S, Larsson B, Narbro K, Sjöström CD, Sullivan M, Wedel H \& Swedish Obese Subjects Study Scientific Group . Lifestyle, diabetes, and cardiovascular risk factors 10 years after bariatric surgery. New England Journal of Medicine 2004351 2683-2693. (doi:10.1056/NEJMoa035622)

6 Utzschneider KM, Carr DB, Barsness SM, Kahn SE \& Schwartz RS. Diet-induced weight loss is associated with an improvement in beta-cell function in older men. Journal of Clinical Endocrinology and Metabolism 200489 2704-2710. (doi:10.1210/jc.2003031827)

7 Villareal DT, Banks MR, Patterson BW, Polonsky KS \& Klein S. Weight loss therapy improves pancreatic endocrine function in obese older adults. Obesity 200816 1349-1354. (doi:10.1038/ oby.2008.226)

8 Kitabchi AE, Temprosa M, Knowler WC, Kahn SE, Fowler SE, Haffner SM, Andres R, Saudek C, Edelstein SL, Arakaki R, Murphy MB, Shamoon H \& Diabetes Prevention Program Research Group . Role of insulin secretion and sensitivity in the evolution of type 2 diabetes in the diabetes prevention program: effects of lifestyle intervention and metformin. Diabetes $2005 \mathbf{5 4}$ 2404-2414. (doi:10.2337/diabetes.54.8.2404)

9 Carr DB, Utzschneider KM, Boyko EJ, Asberry PJ, Hull RL, Kodama K, Callahan HS, Matthys CC, Leonetti DL, Schwartz RS, Kahn SE \& Fujimoto WY. A reduced-fat diet and aerobic exercise in Japanese Americans with impaired glucose tolerance decreases intra-abdominal fat and improves insulin sensitivity but not betacell function. Diabetes 200554 340-347. (doi:10.2337/diabetes. 54.2.340)

10 Morinigo R, Lacy AM, Casamitjana R, Delgado S, Gomis R \& Vidal J. GLP-1 and changes in glucose tolerance following gastric bypass surgery in morbidly obese subjects. Obesity Surgery 2006 16 1594-1601. (doi:10.1381/096089206779319338)

11 Salinari S, Bertuzzi A, Asnaghi S, Guidone C, Manco M \& Mingrone G. First-phase insulin secretion restoration and differential response to glucose load depending on the route of administration in type 2 diabetic subjects after bariatric surgery. Diabetes Care 200932 375-380. (doi:10.2337/dc08-1314)

12 Guldstrand M, Ahren B \& Adamson U. Improved beta-cell function after standardized weight reduction in severely obese subjects. American Journal of Physiology. Endocrinology and Metabolism 2003 284 E557-E565. (doi:10.1152/ajpendo.00325.2002)

13 Goldfine AB, Mun EC, Devine E, Bernier R, Baz-Hecht M, Jones DB, Schneider BE, Holst JJ \& Patti ME. Patients with neuroglycopenia after gastric bypass surgery have exaggerated incretin and 
insulin secretory responses to a mixed meal. Journal of Clinical Endocrinology and Metabolism 200792 4678-4685. (doi:10. 1210/jc.2007-0918)

14 Service GJ, Thompson GB, Service FJ, Andrews JC, CollazoClavell ML \& Lloyd RV. Hyperinsulinemic hypoglycemia with nesidioblastosis after gastric-bypass surgery. New England Journal of Medicine 2005353 249-254. (doi:10.1056/NEJMoa043690)

15 Hofsø D, Nordstrand N, Johnson LK, Karlsen TI, Hager H, Jenssen T, Bollerslev J, Godang K, Sandbu R, Røislien J \& Hjelmesæth J. Obesity-related cardiovascular risk factors after weight loss: a clinical trial comparing gastric bypass surgery and intensive lifestyle intervention. European Journal of Endocrinology 2010163 735-745. (doi:10.1530/EJE-10-0514)

16 Hofsø D, Ueland T, Hager H, Jenssen T, Bollerslev J, Godang K, Aukrust P, Røislien J \& Hjelmesæth J. Inflammatory mediators in morbidly obese subjects: associations with glucose abnormalities and changes after oral glucose. European Journal of Endocrinology 2009161 451-458. (doi:10.1530/EJE-09-0421)

17 Alberti KG \& Zimmet PZ. Definition, diagnosis and classification of diabetes mellitus and its complications. Part 1: diagnosis and classification of diabetes mellitus provisional report of a WHO consultation. Diabetic Medicine 199815 539-553. (doi:10.1002/ (SICI) 1096-9136(199807)15:7< 539::AID-DIA668> 3.0.CO;2-S)

18 Matthews DR, Hosker JP \& Rudenski AS. Homeostasis model assessment: insulin resistance and beta-cell function from fasting plasma glucose and insulin concentrations in man. Diabetologia 198528 412-419. (doi:10.1007/BF00280883)

19 Belfiore F, Iannello S \& Volpicelli G. Insulin sensitivity indices calculated from basal and OGTT-induced insulin, glucose, and FFA levels. Molecular Genetics and Metabolism 199863 134-141. (doi:10.1006/mgme.1997.2658)

20 Stumvoll M, Van HT, Fritsche A \& Gerich J. Oral glucose tolerance test indexes for insulin sensitivity and secretion based on various availabilities of sampling times. Diabetes Care 200124 796-797. (doi:10.2337/diacare.24.4.796)
21 Kahn SE, Prigeon RL, McCulloch DK, Boyko EJ, Bergman RN, Schwartz MW, Neifing JL, Ward WK, Beard JC \& Palmer JP. Quantification of the relationship between insulin sensitivity and beta-cell function in human subjects. Evidence for a hyperbolic function. Diabetes 199342 1663-1672. (doi:10.2337/diabetes. 42.11.1663)

22 Larsson H \& Ahren B. Relative hyperproinsulinemia as a sign of islet dysfunction in women with impaired glucose tolerance. Journal of Clinical Endocrinology and Metabolism $1999 \mathbf{8 4} 2068$ 2074. (doi:10.1210/jc.84.6.2068)

23 Fritsche A, Madaus A, Stefan N, Tschritter O, Maerker E Teigeler A, Haring H \& Stumvoll M. Relationships among age, proinsulin conversion, and beta-cell function in nondiabetic humans. Diabetes 200251 S234-S239. (doi:10.2337/diabetes. 51.2007.S234)

24 Weyer C, Hanson K, Bogardus C \& Pratley RE. Long-term changes in insulin action and insulin secretion associated with gain, loss, regain and maintenance of body weight. Diabetologia $2000 \mathbf{4 3}$ 36-46. (doi:10.1007/s001250050005)

25 Laferrere B, Teixeira J, McGinty J, Tran H, Egger JR, Colarusso A, Kovack B, Bawa B, Koshy N, Lee H, Yapp K \& Olivan B. Effect of weight loss by gastric bypass surgery versus hypocaloric diet on glucose and incretin levels in patients with type 2 diabetes. Journal of Clinical Endocrinology and Metabolism 200893 2479-2485. (doi:10.1210/jc.2007-2851)

26 Swarbrick MM, Stanhope KL, Austrheim-Smith IT, Van L, Ali MR, Wolfe BM \& Havel PJ. Longitudinal changes in pancreatic and adipocyte hormones following Roux-en-Y gastric bypass surgery. Diabetologia 200851 1901-1911. (doi:10.1007/s00125-0081118-5)

Received 6 October 2010

Accepted 15 November 2010 